\title{
Beast Chasers: A 3D PC-based Third Person Action RPG Game used to Spread Societal Issue Awareness
}

\author{
Tyrone N. Luluquisin, Krizza Mae D. Castillo, Kino M. Ligayo, Ian Vince N. Obille, John Kenneth
}

\author{
V. Wong, Manuel B. Garcia, and Maria Rona L. Perez ${ }^{+}$ \\ FEU Institute of Technology, Philippines
}

\begin{abstract}
In the video game industry, games are purposely developed and designed for entertainment, but with the innovative technology we have right now, various video games have been created that are not just for entertainment. Nowadays there are video games for education, medical rehabilitation, awareness campaigns, and applications that target a specific type of illness or impairment or simply to enhance the way of life. To motivate people with these predicaments, gaming has been modified to offer not only entertainment but also a way to help others. The proposed game entitled Beast Chasers — an Action Role Playing Game (ARPG) for PC Platform will make use of symbolism and deep storyline as an instrument to deliver societal issue awareness. The proponents used the Analysis of Variance (ANOVA) to figure out which age group, gender, or economic level will be most interested in the game as the project's target audience. The proponents used Convenience Sampling because it is considerably faster and easier to get findings. To assess the game impact, a questionnaire based on the Likert Scale was given to 30 people and it is used to measure opinions or perceptions about the game and it can also identify where the areas of the game can improve. The results of the game evaluation received a total of 5.54 mean implying that the game was quite satisfying and that the sample was enthusiastic about the game. Therefore, Beast Chasers has promoted and raised an awareness about the Societal Issues that the world is dealing with also making it into a form of ARPG Video Game.
\end{abstract}

Keywords: Action Role Playing Game (ARPG), Societal Issue Awareness, Awareness Campaigns, Education, Medical Rehabilitation

\section{Introduction}

On a global scale, society has been facing issues and problems such as the global economy, poverty, and inequality, climate change, to name a few [1]. In a pursuit of solving these issues, experts and professionals have been trying to produce innovative countermeasures. In the video game industry, GameTeen [2] have been reported to be a promising tool that can help on solving societal issues and although video games are intentionally created and optimized for entertainment, there are various creative gaming applications that support other fields and markets, such as education, medical recovery, and awareness campaigns.

Hence, to contribute to the existing games with deeper purpose rather than the entertainment alone, this paper intends to develop an ARPG (Action Role-Playing Game) computer video game entitled "Beast Chasers", where will make use of symbolism and deep storyline as an instrument to deliver insight and awareness for the player while still offering an immersive gaming experience. The target of the game is to raise awareness about the societal issues happening around (e.g., Depression, Substance Abuse, SelfAcceptance). The project will use a Quantitative Approach through the Likert Scale Questionnaire that revolves around video game-related factors such as gameplay, aesthetics, user interface, audio, story, and website (FURPS).

\footnotetext{
+ Corresponding author. Tel.: + (02) 82818888;

E-mail address: ronaloboperez@gmail.com
} 


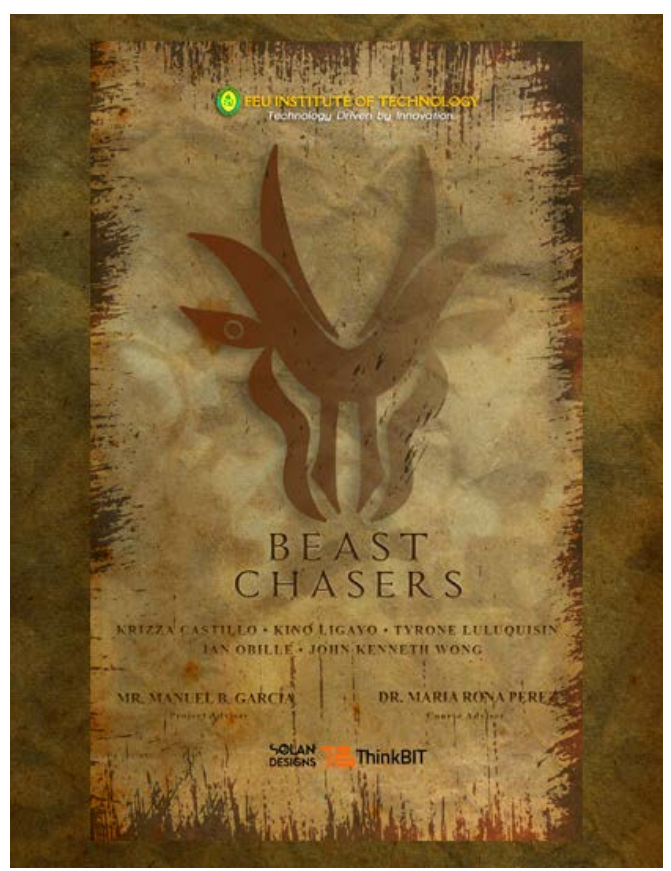

Fig. 1: Official Beast Chasers Poster

\section{Related Literature and Games}

Societal Issues can impact many aspects in one's life. It is an issue that people will need to deal with doing so will not just benefit the people with these issues but for us as a society.

Some of the Societal Issues that the game covers are Poverty, Substance Abuse, and Self-Acceptance. [3] Poverty has many effects and consequences on our society. Impoverish communities suffer from discrimination and will end up in a cycle that continues to perpetuate it. [4] Substance abuse has been an ongoing problem that spans hundreds of years from different parts of the world.[5] People who abuse substances have varied and complicated reasons or the cause of substance abuse stems from a person's childhood or adolescent years. [5] These can lead to people with a lack of self-acceptance [6] where selfacceptance introduces its first counterpart, self-depreciation. As self-depreciation mislabel one's self-worth to be hopeless and it leads to a conclusion that everything about themselves is bad which gives low selfesteem and self-acceptance.

With the game's theme of people being able to rehabilitate back into society, it is important to see the impact that video games have in terms of it. As video games are becoming more accessible to more people, they have been a great help for people with health disabilities as a therapy.

[7] It is suggested that commercial video games, which were mainly designed to be for entertainment with no intentions of being used as therapy, have the potential to be used in preventative and therapeutic medicine. [8] The therapeutic effects of video games are undeniable as more and more games are being used to help people in therapy.

\section{Materials and Method}

The video game described below was named "Beast Chasers" - a third-person point of view video game designed to foster awareness on societal issues in society. Designed for the PC platform, the game is about Tina, the protagonist who wants to prove that she is capable of helping despite her lack of any bestial aspect. She joins the Beast Chaser as an opportunity to show that she does not need any kind of bestial aspect to be useful. 
Table 1: Game levels of Beast Chasers

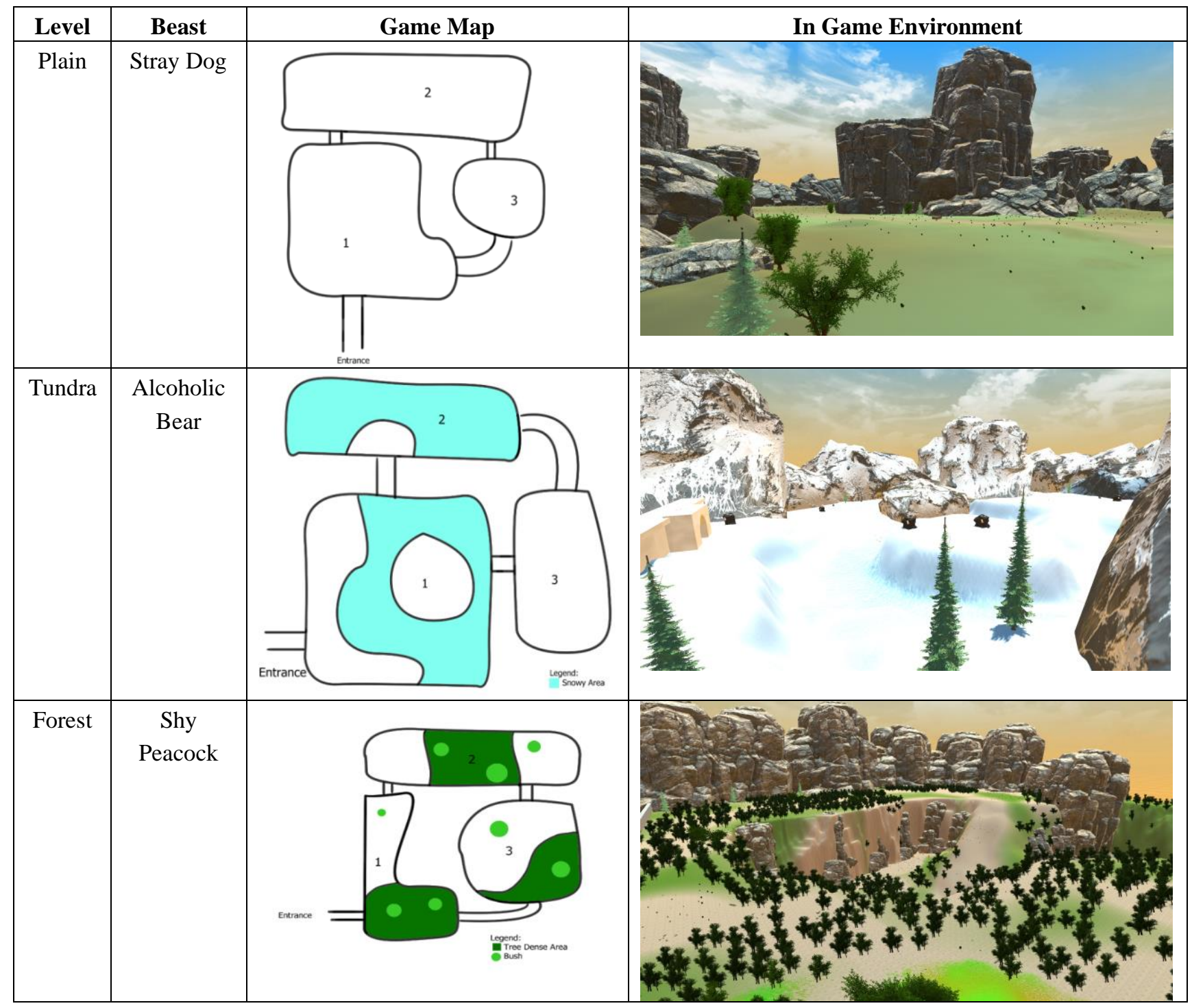

\subsection{Game Mechanics}

Beast Chasers is composed of 3 levels (see Table 1), where the player is tasked to capture 1 beast for each levels, the flow of each level will undergo 5 phases to properly convey the story of the game, these phases are the briefing introduces the current level, the investigation is where the player will be gathering information about the beast that the player will be facing, preparation is where the player prepares for when they face the beast, combat is where the player now must fight and capture the beast, epilogue will show the outcome of the beast and the end of a level.

Each beasts have their own moves and attack patterns making the game more challenging for the player. For example: Shy Peacock (see Fig. 2) has the power to use his agility to invade and continuously attack the player.

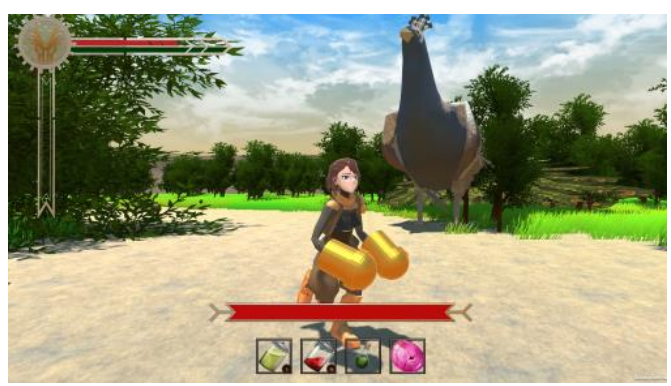

Fig. 2: Tina fighting the Shy Peacock boss 


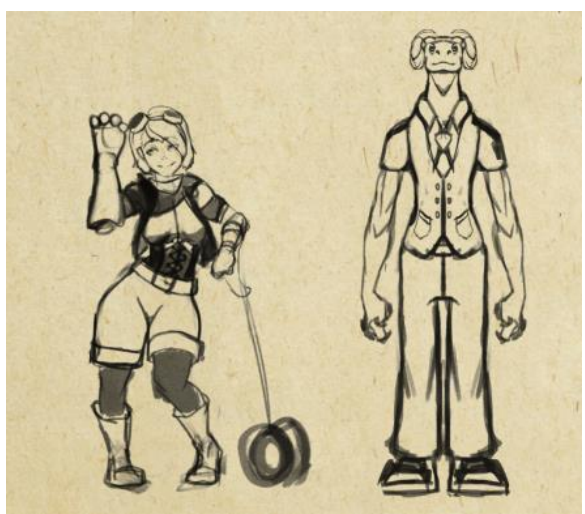

Fig. 3: Tina the Protagonist and Chief

\subsection{Characters and Game Premise}

Set in a fantasy-industrial place where humans and beasts exist. In this world, everyone goes through a phase of turning into a beast when going through adolescence. People going through the phase are sent to the wild to try to keep danger away from civilization. They eventually turn back into a human when going through their adulthood. Not all of them turn back into a human. These beasts will become rabid and uncontrollable. It's the job of the "Beast Chaser" to bring them back to humanity. As the appearance of rabid beasts continues to increase, the Beast Chaser is doing everything to stop attacks from this rabid beast. Tina (see Fig. 2), the protagonist, while not having any kind of bestial aspect, she compensates by using gizmos and weapons to gain the advantage. She joins the Beast Chaser as an opportunity to show that she does not need any kind of bestial aspect to be useful. Tina will not be alone in her journey; there are others in Hearthfire that will help her like The Chief (see Fig. 2). He is the current head of the "Beast Chasers". He handles briefing and he is somewhat of a father figure for Tina. The Alchemist. She helps in the potion making and processing of materials, The Merchant. He buys and sells various materials to help Tina on her missions, The Blacksmith. She is the blacksmith of Hearthfire. She crafts weapons and equipment for Tina to use in her missions. She is a good friend of Tina and will often get ideas for Gizmos from her, and The Oracle. Her vast wisdom can be seen with her massive horns, her bestial aspect, and her tome. She can use foresight and know the status of the land and seeks out by the beast chaser in helping to identify the rabid beast and try to help them overcome the predicament. Throughout the game, the player will be able to learn more about the stories of beasts respectively. Stray Dog symbolizes the Poverty in the game because it shows how cruel and ignorant the people towards the poor, Alcoholic Bear represents the Substance Abuse in the game because it reveals how can strict parents would make the Alcoholic Bear to discreetly go to his friends to party, and lastly, Shy Peacock signifies the Self-Acceptance in the game because it expresses how being bullied could lead to a stressful moment for the reason that the Shy Peacock has different preferences and gender.

\subsection{Game Evaluation and Statistical Treatment}

The evaluation used a quantitative approach through the Likert scale questionnaires: it is mostly used for scaling responses in survey research instrument for the game experience with constructs such as gameplay, aesthetics, user interface, player experience, and audio. To support the quantitative results, qualitative feedback was also collected during playtesting sessions. The Analysis of Variance (ANOVA) is used to determine which age group, sex, or income will high interest in the game as the project as target audience to meet. The Convenience Sampling methodology will be used by the proponents because it is considerably faster and easier to obtain findings. Respondents were invited to attend the Virtual Open House (VOH) where the proponents had numerous respondents watched the proponents showcase their game. A total of thirty (30) respondents that attended the Virtual Open House (VOH) answered the questioners. It is of utmost importance to note that prior to the evaluation, Alpha testing was used to find bugs and test out the features and will be conducted by the developer, Beta Testing was used to polish the code of the project and get hard find a bug, and Compatibility Testing was done to determine the project's compatibility through different platforms and specifications. 


\section{Results and Discussion}

All of the following results of the game evaluation are acquired during the Virtual Open House ( $\mathrm{VOH})$. A total of 30 respondents at the $\mathrm{VOH}$ were obtained by the proponents. The assessment was split into two groups, one being the evaluation of the game and the other the evaluation of the website.

Table 2: Mean summary for game evaluation

\begin{tabular}{|l|c|c|}
\hline \multicolumn{1}{|c|}{ Criteria } & Mean & Verbal Interpretation \\
\hline Gameplay & 4.58 & Strongly Agree \\
\hline Aesthetics & 4.51 & Strongly Agree \\
\hline User Interface & 4.57 & Strongly Agree \\
\hline Audio & 4.46 & Agree \\
\hline Story & 4.59 & Strongly Agree \\
\hline TOTAL & $\mathbf{4 . 5 4}$ & Strongly Agree \\
\hline
\end{tabular}

The gameplay criterion was able to achieve an average of 4.58 , which demonstrates that most respondents strongly agree that the game's mechanics are well balanced, that the game's controls during battle are sensitive, and that the enemy's animations are well telegraphed and simple to understand. Furthermore, the aesthetics criterion was able to obtain an average of 4.51 , which demonstrates that most respondents thoroughly believe that the game's stylized art style is pleasing, that the game uses innovative character designs, and that the characters and environments complement each other. Moreover, the user interface criterion was able to reach an average of 4.57 , indicating that most respondents strongly agree that the heads-up display of the game is well-positioned and easy to interpret, that the user interface of the game suits the game's art design, and that it is easy to access menus and inventory. Additionally, the audio criterion was able to hit an average of 4.46, which indicates that most respondents agree that the user of the game's background music is acceptable and takes advantage of the situation, that the game's sound effects are welltimed and impactful, and that there is a variation in the background music between each level. Lastly, the story criterion was able to hit an average of 4.59 , meaning that most respondents agree that the game accurately represents real-life social challenges, the story of the game is well-paced and easy to comprehend, and the research context of the game helped them understand the game's storyline.

Overall, the capstone project game was able to get an average of 4.54 , suggesting that the game was highly satisfactory and the sample was strongly agreed to the game. This suggests that most of the respondents are pleased with the game, but the game is also open to more enhancement and refinement to make the game better than before.

\section{Conclusion}

It is important to see the influence of video games in terms of the game's concept of individuals being able to rehabilitate back into society. For certain people, video games are most commonly used as entertainment, but since it is an immersive platform, it has the ability to be an interactive medium. Thus, Beast Chasers aims to raise awareness about societal issues (focusing on Poverty, Substance Abuse and SelfAcceptance) through the deep and immersive story line of the game. The process to get a result for the objectives of the game was made through an open house and provided survey with a game criteria and website evaluation. With the result of the open house and survey, Beast Chasers was successful in promoting awareness about the societal issues that our world has.

\section{References}

[1] Bhargava, V. (2006). Introduction To Global Issues

[2] Villani, D., Carissoli, C., Triberti, S., Marchetti, A., Gilli, G., \& Riva, G. (2018). Videogames for Emotion Regulation: A Systematic Review.

[3] Berrebi D. (2011), Effects of Poverty on Society, Health, Children and Violence. 
[4] ACC Staff (2019). History of Substance Abuse Rehabilitation.

[5] Dryden-Edwards, R. (2019). Substance Abuse

[6] Bernard M.E., Vernon A., Terjesen M., \& Kurasaki, R. (2013) Self-Acceptance in the Education and Counseling of Young People. In: Bernard M. (eds) The Strength of Self-Acceptance. Springer, New York, NY.

[7] Colder Carras M, Van Rooij AJ, Spruijt-Metz D, Kvedar J, Griffiths MD, Carabas Y and Labrique A (2018) Commercial Video Games As Therapy: A New Research Agenda to Unlock the Potential of a Global Pastime. Front. Psychiatry 8:300. doi: 10.3389/fpsyt.2017.00300

[8] Franco GE (2016) Videogames and Therapy: A Narrative Review of Recent Publication and Application to Treatment. Front. Psychol. 7:1085. doi: 10.3389/fpsyg.2016.01085 